\title{
EFEITO DO PARASITISMO POR Haemonchus contortus SOBRE O METABOLISMO OXIDATIVO DE LEUCÓCITOS DE OVINOS
}

\section{PARASITIC EFFECT BY Haemonchus contortus ON LEUKOCYTE OXIDATIVE METABOLISM}

\author{
Heloisa Godoi Bertagnon ${ }^{1 *}$ ORCID http://orcid.org/0000-0002-6983-1000 \\ Desiree Vera Pontarolo ${ }^{1}$ ORCID http://orcid.org/0000-0003-3790-6335 \\ Angela Maria Reck ${ }^{1}$ ORCID http://orcid.org/0000-0001-8064-6669 \\ Yohhane Tracy Hofmann Nascimento ${ }^{1}$ ORCID http://orcid.org/0000-0003-3779-1961 \\ Mariana Marcantonio Coneglian ${ }^{1}$ ORCID http://orcid.org/0000-0002-9443-4306 \\ Meire Christina Seki ${ }^{1}$ ORCID http://orcid.org/0000-0001-8813-3948 \\ Alessandra Mayer Coelho ${ }^{1}$ ORCID http://orcid.org/0000-0003-2811-3149 \\ Bruna Artner ${ }^{1}$ ORCID http://orcid.org/0000-0002-5083-2556
}

${ }^{1}$ DEVET/Unicentro, Guarapuava, PR, Brasil

*Autora para correspondência - hbertagnon@hotmail.com

\begin{abstract}
Resumo
A resposta imune tardia direcionada para eliminação da hemoncose pode ser modulada pelo perfil Th2, sendo os eosinófilos as principais células efetoras responsáveis pela eficiente eliminação do parasita; ou modulada pelo perfil Th1, sendo os neutrófilos as principais células efetoras, que promovem eliminação parasitária mais deficiente, pois testes in vitro demonstraram que o parasita deprime o metabolismo oxidativo dos fagócitos. Desta maneira, este trabalho objetivou avaliar se o grau de infecção parasitária observado pela quantidade de ovos por grama de fezes (OPG) de Haemonchus contortus interfere no leucograma e se impacta no metabolismo oxidativo leucocitário em ovino naturalmente acometido por hemoncose. Para tanto, 39 ovinos machos adultos e sem alterações no exame físico, excetuando-se a coloração das mucosas, foram separados em 4 grupos conforme a infecção parasitária 0-350 (n=15), 400 a $1000(n=10), 1100-2000(n=7)$ e 2100-4700 $(\mathrm{n}=7)$. Notou-se correlação significativa positiva entre $\mathrm{OPG}$ e neutrófilos $(\mathrm{r}=0,56 ; \mathrm{P}=0,0003)$ e significativa negativa entre $\mathrm{OPG}$ e eosinófilos ( $\mathrm{r}=-0,50 ; \mathrm{P}=0,0012)$ e $\mathrm{OPG}$ e metabolismo oxidativo leucocitário $(\mathrm{P}=0,0001)$, permitindo concluir que há relação entre as células efetoras e a severidade de infecção parasitária em ovinos naturalmente infectados por hemoncose. Também se verificou que a alta infecção parasitária promove diminuição do metabolismo oxidativo de leucócitos.
\end{abstract}

Palavras-chave: Helmintos; metabolismo oxidativo; neutrófilos; eosinófilos.

\begin{abstract}
The immune response to hemoncosis can be modulated by the Th2 profile, and the main effector cells responsible are eosinophils responsible for a efficient elimination of the parasite, but when it is modulated by the Th1 profile, neutrophils are the main effector cells, responsible for a more deficient parasitic elimination, probabely, because in vitro tests have shown that the parasite depresses the oxidative metabolism of phagocytes. Thus, this study aimed to evaluate if the degree of parasitic infection observed by the amount of eggs per gram of feces (EPG) of Haemonchus contortus interferes in the leukogram, and if it impacts on leukocyte oxidative metabolism in sheep naturally affected by hemoncosis. 39 adult male sheep without alterations in the physical examination, except for mucosal collor, were separated into 4 groups according to
\end{abstract}


parasitic infection 0-350 $(n=15), 400$ to $1000(n=10), 1100 .-2000(n=7)$ and 2100-4700 $(n=7)$. Significant positive correlation was observed between $\mathrm{EPG}$ and neutrophils $(\mathrm{r}=0.56 \mathrm{P}=0.0003)$ and significant negative correlation between EPG and eosinophils $(r=-0,56, P=0.0012)$ and EPG and leukocyte oxidative metabolism $(\mathrm{P}=0.0001)$, allowing to conclude that there is a relationship between effector cells and the severity of parasitic infection in sheep naturally infected with hemoncose, and the high parasitic infection promotes decreased leukocyte oxidative metabolism.

Keywords: Helminths; oxidative metabolism; neutrophils; eosinophils.

Recebido em:10 de novembro de 2017

Aceito em: 4 de setembro de 2109.

\section{Introdução}

As endoparasitoses gastrintestinais constituem o principal fator limitante para a produção de ovinos em todo o mundo ${ }^{(1)}$ devido a: diminuição do ganho de peso, redução das taxas reprodutivas, menor conversão alimentar, diminuição da imunidade e até morte das categorias mais susceptíveis ${ }^{(1)}$.

Entre os vários parasitas que afetam os pequenos ruminantes, o Haemonchus contortus é o de maior prevalência. Trata-se de um nematoide gastrointestinal hematófago que causa diversos graus de anemia e hipoproteinemia nos animais ${ }^{(1,2)}$. Estes helmintos não se distribuem de maneira uniforme no rebanho, gerando diferentes graus de carga parasitária, caracterizando os animais como resistentes ou susceptíveis ${ }^{(1)}$, possivelmente em função da resposta imunológica dos animais ${ }^{(3,4,)}$.

Há diferenças na efetividade da eliminação parasitária entre os animais, tanto em relação a respostas imunes inespecíficas como específicas, fato que tem sido estudado como possível marcador para seleção de ovinos resistentes dentro dos plantéis ${ }^{(3,4,5)}$. Quando os animais mostram uma resposta com perfil Th2, eosinófilos e mastócitos são as células efetoras principais, que ao se degranularem paralisam o parasita e aumentam o peristaltismo intestinal, eliminando os parasitas de forma eficiente ${ }^{(5,6)}$. Já quando direcionam para um perfil Th1, os neutrófilos são as células efetoras, que lisam e expulsam os parasitas por meio do metabolismo oxidativo, de forma menos eficiente em comparação a resposta promovida pelos eosinófilos ${ }^{(5)}$.

Cabe ressaltar ainda os mecanismos de evasão parasitária. Em estudos in vitro, foi verificado que o parasita adulto e as larvas no quarto estágio de Haemonchus contortus inibem o metabolismo oxidativo de neutrófilos e monócitos ${ }^{(9,10)}$. Se tal fato realmente ocorrer em infecções naturalmente adquiridas, é possível que os animais susceptíveis, que usam neutrófilos como principal célula efetora para eliminação desses parasitas, além de apresentarem menor eficiência em sua eliminação, ainda apresentam uma diminuição de imunidade celular inata, tornando-os mais susceptíveis a infecções bacterianas. Embora esse mecanismo de ação ainda não tenha sido estudado, Adeyemi et al. ${ }^{(7)}$ observaram correlação positiva entre a alta infecção por hemoncose e incidência de pneumonia granolumatosa em cabras, inferindo que esta parasitose promoveu redução da imunidade, favorecendo a ocorrência desta comorbidade.

Desta forma, o objetivo deste trabalho foi avaliar se o grau de infecção por Haemonchus contortus identificada por contagem de ovos grama de fezes (OPG) interfere no leucograma e no metabolismo oxidativo de leucócitos sanguíneos de ovino naturalmente acometido por hemoncose.

\section{Material e métodos}

Este projeto foi aprovado pelo comitê de ética em uso de animal, protocolo 01/2016- CEUA/UNICENTRO. 
O experimento foi realizado com 45 ovinos machos adultos ( 7 a 13 meses), das raças Texel e/ou Corriedale com bom escore corporal (40 a $60 \mathrm{~kg} /$ peso vivo), no período de novembro de 2016 a fevereiro de 2017. Os animais eram oriundos de cinco propriedades criatórias da região de Guarapuava, todas com manejo semiintensivo semelhante, no qual os animais eram soltos às 9 horas da manhã, em pasto de quicuio (Brachiaria humidícula) e recolhidos ao entardecer, em apriscos não ripados, de terra batida ou cimento, rapados quinzenalmente. Os animais recebiam sal mineral próprio para a espécie e quirera de milho $(0,5 \mathrm{~kg} / \mathrm{animal})$. Durante os três meses que antecederam o experimento, não sofreram nenhuma intervenção como vermifugação, tratamentos medicamentosos, cirúrgicos ou vacinação.

Para tanto, selecionou-se apenas animais com as funções vitais dentro dos parâmetros da normalidade, com exceção de coloração de mucosas, que não foi avaliada. Apenas em um momento amostras de fezes foram recolhidas digitalmente da ampola retal desses animais. Além disso, amostras de sangue foram colhidas por venopunção da jugular. Estas amostras foram colhidas em frascos a vácuo contendo ácido etilenodiamino tetraacético (EDTA) para execução do leucograma, dosagem de proteína e fibrinogênio sérico, com o anticoagulante heparina sódica, para execução das provas de metabolismo oxidativo. Todas as amostras foram transportadas refrigeradas até a Universidade Estadual do Centro-Oeste, Campus CEDETEG, para processamento laboratorial, não excedendo 4 horas entre a coleta e a análise do metabolismo oxidativo.

Como critério de inclusão amostral, foram utilizados apenas animais com leucograma até 12.000 células $/ \mathrm{mm}^{3}$, com relação mononucleares e polimorfonucleares $1 / 3$ a 2/3, proteína entre 6 a 7,9 g/dL e com fibrinogênio abaixo de $0,5 \mathrm{~g} / \mathrm{dL}^{(11)}$.

Os animais foram agrupados conforme o OPG de Haemonchus contortus em um dos grupos a seguir: Grupo 1: 0-350, Grupo 2: 400-1000, Grupo 3: 1100-2000 e Grupo 4: 2100-4700, de acordo com prévios experimentos, com modificação ${ }^{(4,6)}$.

O leucograma foi realizado por contagem manual em câmara de Neubauer e a diferencial por características morfofuncionais das células de esfregaços sanguíneos corados com conjunto de corante para hematologia (Panóptico rápido LB, Centerlab, MG, Brasil), avaliando-se 100 células em microscopia ótica em lente de imersão, realizado por um observador treinado em sistema cego em relação ao grupo experimental. As dosagens de fibrinogênio foram realizadas pelo método de precipitação pelo calor a $56{ }^{\circ} \mathrm{C}$ e lido em refratômetro (Biobrix, Modelo 301), assim como a proteína total ${ }^{(11)}$.

O metabolismo oxidativo de leucócitos sanguíneos foi mensurado pela técnica colorimétrica de nitroazul de tetrazolio (NBT) com modificações ${ }^{(12)}$. Resumidamente, $100 \mu \mathrm{L}$ do sangue total foi incubado com partes iguais com solução de NBT a 1\% (Sigma ${ }^{\circledR}$ ), estimuladas com $5 \mu \mathrm{L}$ de 12 miristato 13 acetato de forbol (PMA, 300 ng/mL, Sigma $\left.{ }^{\circledR}\right)$, por 30 minutos, a $37^{\circ} \mathrm{C}$, em tubos de vidro. Após a parada da reação, por adição de 2000 $\mu \mathrm{L}$ de EDTA (3mM) gelado, as hemácias foram rompidas por lise osmótica. O NBT externo foi removido após lavagem com metanol (Synth $\left.{ }^{\circledR}\right)$ e as células foram dissolvidas com KOH (Synth $\left.{ }^{\circledR}\right)(3 \mathrm{M}, 120 \mu \mathrm{L})$ e DMSO (Dimesol@ - MarcoLab) $(99 \%, 140 \mu \mathrm{L})$, e então transferidas para microplacas de fundo chato com 96 poços. A leitura da densidade óptica (DO) foi realizada em comprimento de onda igual a $620 \mathrm{~nm}$ (Thermo Plate TP - Reader $^{\circledR}$ ). As amostras foram feitas em duplicatas utilizando-se a média dos resultados para cada animal, com índice de intravariabilidade menor que 5\%, sendo que essas duplicatas foram testadas no máximo três vezes.

Para amostras de fezes, utilizou-se para a contagem de ovos por grama de fezes a técnica McMaster modificada ${ }^{(13)}$. Na sequência, foi realizada a coprocultura com vermiculita por meio da técnica de Roberts e O'Sullivan, descrita por Ueno e Gonçalves ${ }^{(14)}$, sendo o material incubado em estufa B.O.D. por um período de sete dias, à temperatura de $25^{\circ} \mathrm{C}$, com controle diário da umidade. Após o período de incubação, as larvas de terceiro estágio foram recuperadas em água corrente e em placa de petri e posteriormente identificadas através de microscopia óptica conforme as características morfológicas, com auxílio de chaves de identificação ${ }^{(14)}$. De 
acordo com a porcentagem de larvas de $H$. contortus identificada, corrigiu-se o OPG para a quantidade de ovos de $H$. contortus por grama de fezes.

A análise estatística dos dados foi realizada utilizando o software estatístico Instat Graphpad. Os dados foram avaliados pelo teste de normalidade, pelo teste de Kolmogoroc e Smirnov, pelo teste de variância e pelo teste de Barllet. Todos os resultados tiveram distribuição normal e foram analisados pela ANOVA de variância e pelo teste Tukey, como pós-testes. Os dados de OPG foram correlacionados com neutrófilos, eosinófilos e metabolismo oxidativo pelo teste de correlação de Pearson. Para todos os resultados, foram consideradas significantes as análises que apresentaram $\mathrm{p} \leq 0,05$.

\section{Resultados e discussão}

Optou-se por estudar machos adultos sem alterações no exame físico, com exceção de alterações da coloração de mucosas, as quais não foram avaliadas para não excluir os animais susceptíveis. Estudou-se ainda ovinos sem alterações no leucograma, proteína plasmática e fibrinogênio com intuito de controlar o estudo, diminuindo assim o máximo possível de variáveis além da hemoncose, como gestação, parto, desmame, transporte, tosquia, tratamentos prévios e vacinações, que pudessem interferir nas análises ${ }^{(15)}$. Desta maneira, optou-se por trabalhar com machos adultos que foram submetidos aos critérios de inclusão, restando 39 animais dos 45 coletados.

Como estes animais foram mantidos numa pastagem natural ao longo do ano, assume-se que estavam expostos a doses iguais de larvas infectantes de Haemonchus sp. oriundas do pasto, o que indicaria sua competência em eliminar ou manter parasitas em seu abomaso ${ }^{(1,4)}$, permitindo, com base nos achados do exame de fezes, separar estes animais nos grupos propostos ${ }^{(4,6)}$.

A contagem de ovos por grama de fezes poderia apresentar limitações quanto à quantificação da infecção real, visto que uma alta densidade de parasitas no abomaso poderia levar a intermitência na ovipostura ou ainda poderia haver parasitas adultos do mesmo sexo dentro do abomaso, o que resultaria em uma falsa OPG negativa. No entanto, esta técnica ainda é a mais utilizada para a identificação da parasitose ${ }^{(4,16)}$. Soma-se a isso que esta é uma técnica que permite selecionar animais resistentes dentro do rebanho, já que na técnica ideal, a contagem dos parasitas no trato gastrointestinal só pode ser realizada após a necrópsia dos animais ${ }^{(5)}$, o que fere a ética e o bem-estar animal, se ocorrer apenas em decorrência deste estudo.

Os resultados referentes ao leucograma dos animais, de acordo com a infecção parasitária, estão contidos na Tabela 1. Tanto as contagens de leucócitos como os neutrófilos, basófilos, linfócitos e monócitos encontravamse dentro dos valores de referência para a espécie ${ }^{(11)}$. Pode-se notar que os animais com maior contagem de ovos por grama de Haemonchus contortus possuíam estatisticamente menor contagem de neutrófilos (Grupo 1 e Grupo 2, diferente do Grupo 4, $\mathrm{P}=0,0008$ ), e o grupo com menor OPG apresentava estatisticamente menor contagem de eosinófilos que os outros grupos ( $\mathrm{P}=0,0001$ ), sendo que 8/15 do Grupo 1, e 1/10 do Grupo 2 apresentaram eosinofilia.

A Figura 1 traz informações a respeito da correlação entre a infecção parasitária e as duas principais células efetoras sanguíneas avaliadas: eosinófilos e neutrófilos. Nota-se correlação significativa proporcional entre o OPG e a contagem absoluta dos neutrófilos $(\mathrm{R}=0,56 ; \mathrm{P}=0,0003)$ e correlação negativa significativa entre $\mathrm{o}$ OPG e a contagem absoluta de eosinófilos ( $\mathrm{R}=-0,50 ; \mathrm{P}=0,0012)$. 
Tabela 1. Leucograma de ovinos conforme a quantidade de ovos de Haemonchus contortus por grama de fezes.

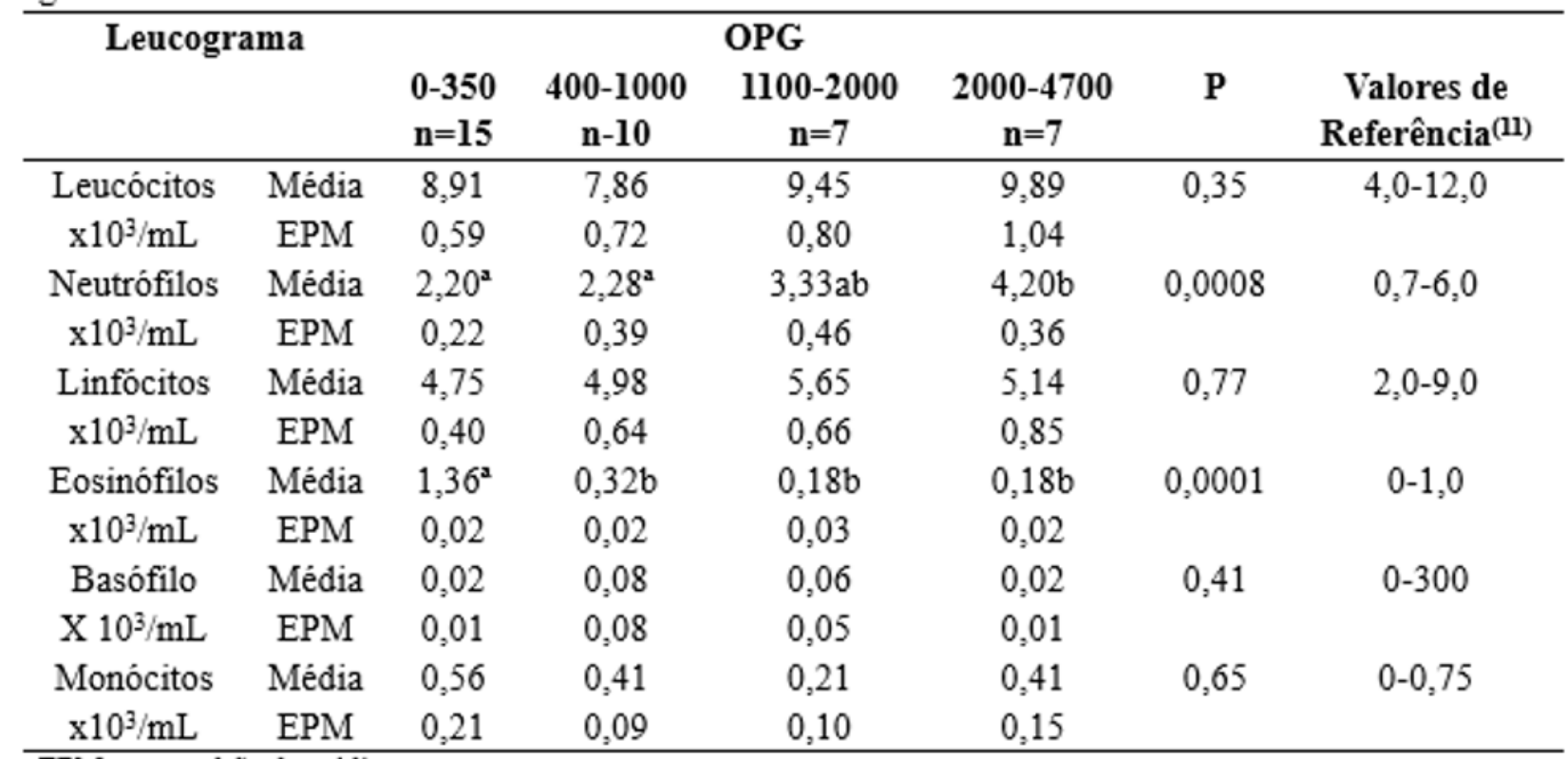

EPM- erro padrão da média.
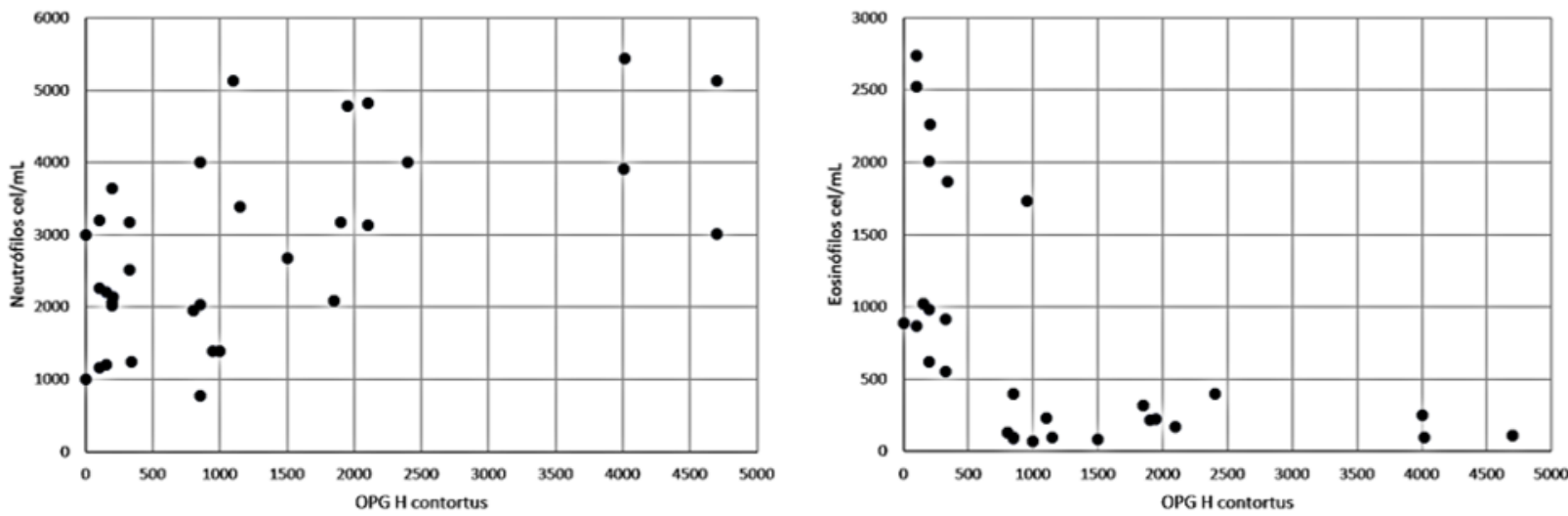

Figura 1. Correlação de Pearson entre a contagem de ovos por grama de fezes de Haemonchus contortus e neutrófilos ou eosinófilos sanguíneos de ovinos.

Desta maneira, o presente trabalho notou que a intensidade da hemoncose, identificada pelo OPG, interferiu na contagem absoluta de neutrófilos e eosinófilos sanguíneos, mas não na contagem dos leucócitos totais e nas demais populações. Ortolani et al. ${ }^{(8)}$ observaram correlação inversa entre o número de parasitas e o número total de leucócitos, notando que ovinos com menor carga parasitária apresentavam maiores contagens de leucócitos, neutrófilos e eosinófilos e menores contagens de linfócitos em comparação aos animais com maior carga parasitária, aos 58 dias após a infecção experimental.

Zaros et al. ${ }^{(6)} \mathrm{e}$ Toscan et al. ${ }^{(16)}$ estudaram apenas os eosinófilos sanguíneos e não o leucograma de ovinos naturalmente infectados por $H$. contortus identificada pelo OPG. Toscan et al. ${ }^{(16)}$ notaram que a diminuição de infecção parasitária promoveu aumento de eosinófilos circulantes, perfil de citocinas $\mathrm{Th} 2 \mathrm{e}$ maiores teores séricos de IgA, IgE e IgG. Já Zaros et al. ${ }^{(6)}$ notaram que a infecção parasitária não influenciou na contagem de eosinófilos, apesar dos animais com menor infecção apresentarem citocinas do perfil Th2 e aqueles com maior infecção apresentarem mais citocinas perfil Th1.

Tais discordâncias de resultados podem ser explicadas pelas respostas imediata e tardia do hospedeiro frente a hemoncose. A resposta imediata e inespecífica inicia-se quando há contato das larvas do terceiro estágio com 
o abomaso, em que mastócitos e leucócitos residentes secretam leucotrienos, histamina e quimiocinas que promovem recrutamento eosinofílico para o local, aumentam a secreção de muco abomasal, gerando hipermotilidade do órgão e culminando na eliminação larval. Ainda há aumento de permeabilidade vascular permitindo extravasamento de anticorpos para o lúmen abomasal.

Quando o estágio larval consegue penetrar nas glândulas abomasais, inicia-se a resposta tardia. Nesta fase, ocorre a resposta imune específica, na qual há ativação da via alternativa do complemento e ativação de linfócitos auxiliares (CD4), responsáveis por deflagar os perfis Th1, que tem como principal célula efetora os neutrófilos, responsáveis por eliminação larval por citotoxicidade, ou o perfil Th2, que tem como principal célula efetora os eosinófilos, responsáveis pela eliminação larval com auxílio de imunoglobulinas, alteração do ambiente abomasal e ainda citotoxicidade dos eosinófilos, mastócitos e macrófagos induzida por $\operatorname{IgE}{ }^{(3,5)}$. Estes diferentes perfis Th1 ou Th2 são afetados por fatores individuais, nutricionais ou fatores parasitários, o que permite selecionar animais resistentes ou susceptíveis de acordo com o perfil definido, quando os animais estão bem nutridos ${ }^{(17)}$, ou até utilizar como método de controle de parasitose, a melhor nutrição dos animais, visto que o maior aporte de nutriente estimulou o perfil Th2 nos ovinos naturalmente acometidos por hemoncose ${ }^{(16)}$. Cabe ressaltar que os animais possuem fatores individuais que determinam o perfil de resposta Th. Logo, apenas a utilização da melhor nutrição não irá necessariamente definir um perfil Th2 em detrimento do Th1 ${ }^{(16)}$.

No trabalho de Ortolani et $a l .{ }^{(8)}$, a infecção foi experimental, portanto os animais infectados possuíam, aos 58 dias de infecção, praticamente a mesma fase de desenvolvimento do parasita, que segundo os autores correspondia a forma adulta desse parasita ${ }^{(8)}$. Já nas infecções naturalmente adquiridas, acredita-se que haja diferentes estágios parasitários no abomaso, deflagrando simultaneamente respostas larvais imediata e tardia, o que poderia explicar as diferenças encontradas na literatura e no presente trabalho.

Na Figura 2, estão presentes os dados da correlação entre a infecção parasitária por hemoncose e o metabolismo oxidativo dos leucócitos sanguíneos dos ovinos. Pode-se observar a correlação negativa e significativa entre o metabolismo oxidativo de leucócitos sanguíneo e a infecção parasitárias ( $\mathrm{r}=-0,76 ; \mathrm{P}=0,0001)$.

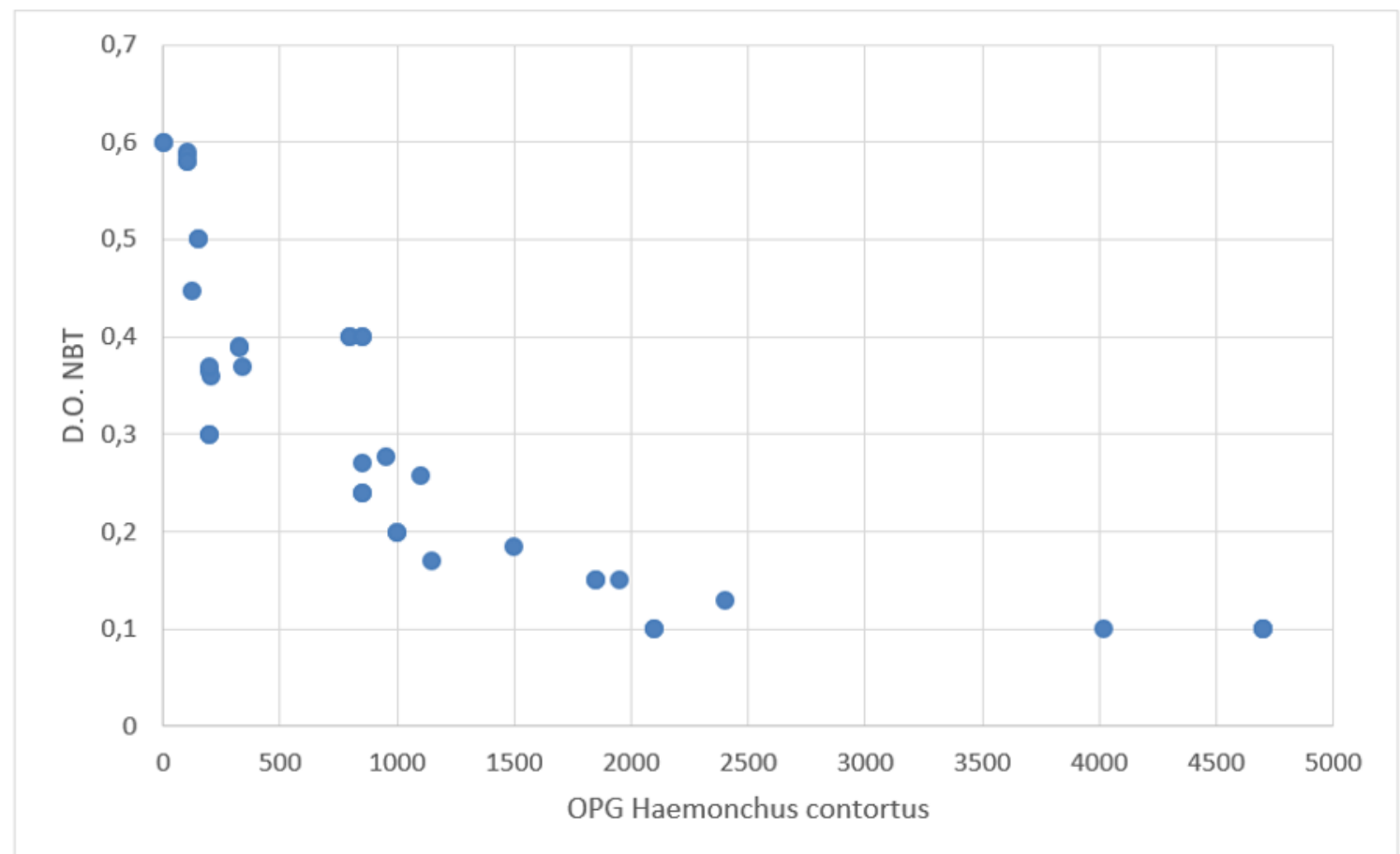

Figura 2. Correlação entre o OPG de Haemonchus contortus e metabolismo oxidativo de leucócitos em ovinos com hemoncose.

A prova colorímétrica de NBT identificou quantitativamente as funções de fagocitose e de metabolismo oxidativo, simultaneamente em fagócitos ${ }^{(12)}$, indicando que quanto maior foi a 
eliminação de ovos de parasita menor foi a função dos fagócitos sanguíneos, caracterizando uma maior chance de ocorrer infecções bacterianas nos animais mais parasitados. Resultados similares foram encontrados por Camargo et al. ${ }^{(18)}$, ao estudarem ovinos com hemoncose induzida experimentalmente.

De acordo com Anbu e Joshi ${ }^{(9)}$, neutrófilos sanguíneos de ovinos incubados com a proteína (gp55), excretada/secretada por parasitas adultos de $H$. contortus, apresentaram inibição do metabolismo oxidativo. Tal fato poderia justificar o motivo pelo qual alguns animais que desenvolveram uma resposta predominantemente neutrofílica tenham tido maior dificuldade em eliminar os parasitas. Esse mecanismo de redução do sistema imune é comum a alguns parasitas, sendo chamado de evasão parasitária, o que permite que os parasitas escapem da ação das enzimas e de fatores metabólicos que naturalmente os matariam ${ }^{(19)}$.

$\mathrm{Na}$ resposta imune inata, a primeira a ser deflagrada, os macrófagos e os neutrófilos têm papel fundamental. Enquanto os macrófagos fagocitam e apresentam os antígenos, as células recrutadas do sangue, os neutrófilos, eliminam as partículas internalizadas principalmente pelo metabolismo oxidativo ${ }^{(20)}$. Desta maneira, a redução da função dos fagócitos sanguíneos além de dificultar a eliminação parasitária dos animais que têm o perfil de resposta Th1, ainda seria responsável pela maior susceptibilidade dos animais parasitados a infecções bacterianas $^{(20)}$. Provavelmente este fato explicaria o motivo pelo qual as cabras com maior infecção por hemoncose apresentaram correlação positiva e significativa com pneumonias naturalmente adquiridas no trabalho de Adeymi e colaboradores ${ }^{(7)}$.

A diminuição da imunidade em ovinos com maior infecção parasitária já foi relatada, e normalmente é associado às perdas de absorção de nutrientes, o que leva à hipoproteinemia, que resulta em redução da atividade imune ${ }^{(16)}$. No presente trabalho, o critério de inclusão adotado permitiu evidenciar que animais parasitados também apresentam redução da atividade dos fagócitos sanguíneos por mais que mantenham um bom escore corporal e valores séricos normais de proteína.

\section{Conclusões}

Neste estudo foi possível verificar que a menor infecção parasitária em ovinos naturalmente infectados com H. contortus promoveu aumento de eosinófilos sanguíneos e a maior infecção parasitária promoveu incremento de neutrófilos sanguíneos, sugerindo que estas respectivas células seriam as principais efetoras para a eliminação parasitária. Concluiu-se também que a alta infecção parasitária promoveu redução do metabolismo oxidativo leucocitário mesmo em animais com bom status nutricional, permitindo inferir que estes animais estariam mais susceptíveis a infecções bacterianas.

\section{Referências}

1. Maia D, Moraes FR, Sotomaior CS revisão da literatura - o método FAMACHA® como tratamento seletivo de pequenos ruminantes. Vet Not. 2013;19(1):41-66.

2. Ruas JL, Berne MEA. Parasitoses por nematóides gastrintestinais em bovinos e ovinos. In Correa RF, Schild AL, Méndez MC, Lemos RA. Doença de ruminantes e eqüinos. São Paulo: Varela, 2001 p.89-117.

3.Zhang R, Liu F, Hunt P, Li C, Zhang L, Ingham A, Li RW. Transcriptome analysis unraveledpotential mechanisms of resistance to Haemonchus contortus infection in Merino sheep populations bred for parasite resistance. Vet. Res. 2019; 50(7): 13 pages 
4.Roy M, Senapati PK, Roy S, Nandi D. Variability of resistance to natural Haemonchus contorts infection vis-à-vis haematological and biochemical parameters in garole sheep. Expl Anim Med Res. 2013;3(2):145153.

5. Alba-Hurtado F, Muñoz-Guzmán Ma. Immune Responses Associated with Resistance to Haemonchosis in Sheep. Biomed Res Int. 2013 Jul Article ID 162158, 11 pages

6. Zaros LG, Neves MRM, Benvenuti CL, Navarro AML, Sider, HL, Coutinho, LL, et al. Response of resistant and susceptible Brazilian Somalis crossbreed sheep naturally infected by Haemonchus contortus. Parasitol Resv.2014;113:1155-1161

7. Adeyemi MT, Morenikeji OA, Emikpe BO, Jarikre TA. Interactions between gastrointestinal parasitism and pneumonia in Nigerian goats J. Parasit. Dis. 2017:41(3):726-733.

8. Ortolani EL, Leal MLR, Minervino AHH, Aires AR, Coop RL, Jackson F et al. Effects of parasitism on cellular immune response in sheep experimentally infected with Haemonchus contortus. Vet Parasitol. 2013;196:230-234.

9. Anbu KA, Joshi P. Identification of a $55 \mathrm{k}$ Da Haemonchus contortus excretory/secretory glycoproteinas a neutrophil inhibitory factor. Parasite Immunol. 2008;30:23-30.

10. Kotze AC. Catalase induction protects Haemonchus contortus against hydrogen peroxide in vitro. Int $\mathrm{J}$ Parasitol. 2003;33:393-400.

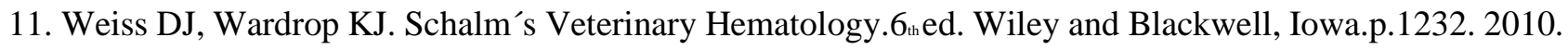

12. Choi HS, Kim JW, Cha YN, Kim C. A Quantitative Nitroblue Tetrazolium Assay for Determining Intracellular Superoxide Anion Production in Phagocytic Cells. J Immunoassay Immunoch. 2006; 27(1): 3144.

13. Monteiro SG. Parasitologia em Medicina Veterinária. $1^{a}$ ed. Editora Roca: São Paulo; 2011, 370p.

14. Ueno H, Gonçalvez PC. Manual para Diagnóstico das Helmintoses de Ruminantes. Japan Int Coop Agency 1998, 4 ed., p. 25-31.

15. Schmiedt LDA, Meirelles AC, Pereira MW, De Oliveira S, Moraes FR. Leucograma como indicador d estresse durante a avaliação parasitológica de ovinos (Ovis aries). Arch Vet Scie. 2013;18(1):46-53.

16.Toscan G, Cadore GC, Limana, JFT, Weber A,; Heinloft HP, Medeiros MFD, Sangioni LA, Vogel, FS. Immune response of sheep naturally infected with Haemonchus spp. on pastures with two different nutritional conditions Semina: Ciências Agrárias. 2017; 38(2): 809-819

17. Pernthaner A, Shaw RJ, Mcneill MM, Morrison L, Hein WR. Total nematode species and IgE responses in intestinal lymph of genetically resistant and susceptible sheep during infection with Trichostrongylus colubriformis. Vet.Immunol.Immunop.2005;104(1): 69-80.

18. Camargo EV, Lopes STA, Costa MM, Paim F, Barbosa CS, Leal MLR. Neutrophil oxidative metabolism and hemogram of sheep experimentally infected with Haemonchus contortus and supplemented with selenium and vitamin E. J Anim Physiol Anim Nutr. 2010;94:1-6.

19.Schmid-Hempel P. 2009. Immune defence, parasite evasion strategies and their relevance for "macroscopic phenomena" such as virulence. Philosophical Transactions of The Royal Society. 364:85-89.

20.Abbas A.K., Litchman A.H., Pillai S. 2012. Cellular and molecular immunology. 8 ed. Philadelphia: Elsevier Saunders. 566. 